Interestingly, serum creatine kinase $\mathrm{BB}$ measured by radioimmunoassay, was abnormal in this patient (figure). Brain-type creatine kinase $\mathrm{BB}$ is present in astrocytes and, at a lower concentration, in other tissues. In cases of proved macroscopic brain injury very high enzyme levels may be detected within hours. ${ }^{3}$ Here, highest levels were observed after 48 hours, possibly when hypoxic cells developed structural changes due to continuing ischaemia. Previously we found transient abnormalities of creatine kinase BB and MB in marathon runners without neurological deficits. ${ }^{4}$ In this instance creatine kinase $\mathrm{MB}$ was normal while the $\mathrm{BB}$ isoenzyme remained high and then fell, correlating with clinical improvement.

BH is in receipt of a grant from the Medical Research Council of Ireland.

' Pedoe DST. Marathon running and creatine kinase levels. Lancet 1982 ;ii 154

2 Thomas DJ. Whole blood viscosity and cerebral blood flow. Stroke 1982; 13:285-7.

${ }^{3}$ Phillips JP, Jones HM, Hitchcock R, Adams N, Thompson RJ. Radioimmunoassay of serum creatine kinase $\mathrm{BB}$ as an index of brain damage after head injury. $\mathrm{Br} \mathrm{Med} \mathcal{F} 1980 ; 281: 777-82$.

4 Phillips J, Horner B, Ohman M, Horgan J. Increased brain-type creatine phosphokinase in marathon runners. Lancet $1982 ; \mathrm{i}: 1310$.

(Accepted 25 October 1982)

Department of Neurosurgery, St Laurence's Hospital, Dublin

JACK PHILLIPS, MD, FRCSI, consultant neurosurgeon

BERNADETTE HORNER, BSC, research assistant

TERENCE DOORLY, $M B$, senior house officer

Department of Neuroradiology, St Laurence's Hospital

JAMES TOLAND, BSC, FRCR, consultant neuroradiologist

\section{Outpatient paediatric fibreoptic proctosigmoidoscopy: possible and useful}

The role of colonoscopy in diagnosis and follow-up of children with chronic inflammatory bowel disease is becoming recognised. ${ }^{1-4}$ In adult practice flexible fibreoptic sigmoidoscopy without sedation and with minimal bowel preparation is a safe and useful investigation. ${ }^{5}$ In assessing adult inflammatory bowel disease conventional rigid proctosigmoidoscopy and rectal biopsy are normally the first-line procedures. In most paediatric centres, however, rigid proctosigmoidoscopy and rectal biopsy are performed only under general anaesthesia and are regarded as major investigations, rarely undertaken. We therefore decided to see if limited fibreoptic proctosigmoidoscopy using a smalldiameter colonoscope would be acceptable to children in a paediatric outpatient clinic and to evaluate its role in the diagnosis and follow-up of children with inflammatory bowel disease.

\section{Patients, methods, and results}

Fibreoptic proctosigmoidoscopy was attempted in 21 children (13 boys and eight girls, age range $4-15$ years, mean age 11 ) attending the paediatric inflammatory bowel disease clinic at St Bartholomew's Hospital between February and May 1982. Fibreoptic proctosigmoidoscopy was added without formality to the routine outpatient physical examination. No prior bowel preparation was given and no sedation was used before, during, or after the procedure. A $1 \mathrm{~cm}$ diameter very flexible paediatric colonoscope with tip designed for comfortable insertion (Olympus PCF) was selected. Patients were examined in the left lateral position. Only limited examination was attempted. Biopsy samples for histological assessment were normally taken at $10 \mathrm{~cm}$ intervals, at least one biopsy specimen being taken from the rectum during each examination.

The instrument was successfully inserted to between 20 and $30 \mathrm{~cm}$ in 20 of the 21 patients. The time for the whole procedure including taking biopsy specimens and teaching was 2-10 minutes (mean 5.6 minutes). One examination was impossible because of impaction of solid faeces. Fifteen of the children felt no discomfort and the remaining five tolerated the procedure, though finding it initially uncomfortable.

In four patients the tissue samples taken were considered inadequate for histological assessment, mainly because of their small size. Nine children showed histological abnormalities, including three in whom the mucosa appeared normal endoscopically. In six patients the results of the examination were thought to have aided clinical management. Five of the patients subsequently underwent total colonoscopy with bowel preparation, in each $\frac{\text { Wo }}{7}$ case giving results compatible with those obtained during the limited examination.

\section{Comment}

This small study shows that fibreoptic proctosigmoidoscopy can be quickly performed in a routine paediatric outpatient clinic and is $\infty$ acceptable to children. It allows the paediatric gastroenterologist to follow the standard practice in adult clinics of rapid inspection of the rectal mucosa and the taking of a rectal biopsy specimen. The $\overline{\bar{G}}$ paediatric colonoscope is smaller in diameter than an examining finger and is considerably more comfortable than the rigid metal instrument. The colonoscope and its light source can be conveniently mounted on a standard metal dressing trolley (figure). The "teaching attachment" side arm allowed some children and parents to appreciate the nature of the clinical problem by watching during the examination, as well as being convenient for discussion with students or medical colleagues. Photographic documentation is easy either for teaching or so as to affix an instant (Polaroid) photograph to the case record.

The only drawback of the paediatric colonoscope used for this study was the small-size forceps biopsy specimens obtained. The importance of taking biopsy samples is considerable; thus multiple samples should be taken in each case.

Though fibreoptic proctosigmoidoscopy gave useful information in these cases, it cannot supplant the additional information given in some cases by total colonoscopy. The occurrence of rectal sparing in Crohn's disease means that a very limited examination with normal biopsy appearances might be misleading, though in our experience there is frequently minor abnormality in the sigmoid colon which is visible on limited examination. Small size is offset by the taking of accurate "target" specimens, which give a high percentage of successful histological diagnosis of Crohn's disease. Whereas total colonoscopy requires considerable experience which may not be available in every paediatric centre, limited examination is very easy to perform and requires little training. Our study convinced us that paediatric fibreoptic proctosigmoidoscopy without sedation or bowel preparation is practicable, well tolerated, and a useful investigation in diagnosis and management of children with possible inflammatory bowel disease.

Requests for reprints should be addressed to: Dr John A Walker-Smith, Department of Child Health, St Bartholomew's Hospital, West Smithfield, London EC1A 7BE.

${ }^{1}$ Liebman WM. Fiberoptic endoscopy of the gastrointestinal tract in infants and children. Am $\mathcal{f}$ Gastroenterol $1977 ; 68: 452-5$.

2 Chong SKF, Bartram CB, Campbell CA, Williams CB, Blackshaw AJ, Walker-Smith JA. Chronic inflammatory bowel disease in childhood. Br Med F 1982;284:101-4.

${ }^{3}$ Rodesch P, Cadranel S, Peeters JP, Cremer N, Cremer M. Colonic endoscopy in children. Acta Paediatr Belg 1976;29:181-4.

4 Williams CB, Lage NJ, Campbell CA, et al. Total colonoscopy in children. Arch Dis Child 1982;57:49-53.

5 Vellacott KD, Hardcastle JD. An evaluation of flexible fibreoptic sigmoidoscopy. $\mathrm{Br} \mathrm{Med} \mathcal{F} 1981$;283:1583-5.

(Accepted 15 October 1982)

Departments of Child Health and Gastroenterology, St Bartholomew's Hospital, London EC1A 7BE

HISHAM NAZER, MRCP, overseas research fellow

JOHN A WALKER-SMITH, FRCP, reader in paediatric gastroenterology KIM DAVIDSON, SRN, outpatient sister, paediatric inflammatory bowel disease clinic

CHRISTOPHER B WILLIAMS, FRCP, consultant physician, department of gastroenterology

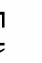
. 